\title{
PENGARUH PELATIHAN KERJA, LINGKUNGAN KERJA DAN KOMITMEN ORGANISASI TERHADAP KINERJA KARYAWAN DI ROYAL HOTEL JEMBER
}

\section{THE EFFECT OF JOB TRAINING, JOB ENVIRONTMEN, ORGANIZATIONAL COMMITMENT ON EMPLOYEES PERFORMANCE AT ROYAL HOTEL JEMBER}

\author{
Lutfiatul Husnah, Trias Setyowati, Wahyu Eko S. \\ Prodi Manajamen Fakultas Ekonomi Universitas Muhammadiyah Jember \\ E-mail: lutfiatulhusnah12@gmail.com, trias@unmuhjember@gmail.com, \\ setianingsih@unmuhjember.ac.id
}

\begin{abstract}
ABSTRAK
Penelitian ini bertujuan untuk mengetahui pengaruh pelatihan kerja, lingkungan kerja dan komitmen organisasi terhadap kinerja karyawan di Royal Hotel Jember. Teknik pengumpulan data menggunakan observasi, wawancara dan kuesioner terhadap 52 responden dengan teknik sensus. Metode penelitian menggunakan penelitian kausal. Hasil penelitian menggunakan uji t, diperoleh nilai koefisien variabel pelatihan kerja (X1) nilai signifikasi hitung sebesar $0,001>0,05$ dan $t_{\text {hitung }}(3,533)>t_{\text {tabel }}(1,677)$, variabel lingkungan kerja $(\mathrm{X} 2)$ nilai signifikasi hitung sebesar $0,003>0,05$ dan $t_{\text {hitung }}(3,125)>t$ tabel $(1,677)$, dan variabel komitmen organisasi (X3) nilai signifikasi hitung sebesar $0,032>0,05$ dan $\mathrm{t}$ hitung $(2,208)>\mathrm{t}$ tabel $(1,677)$. Sehingga penelitian ini menunjukkan bahwa pelatihan kerja berpengaruh signifikan terhadap kinerja karyawan Royal Hotel Jember, lingkungan kerja berpengaruh signifikan terhadap kinerja karyawan Royal Hotel Jember, dan komitmen organisasi berpengaruh signifikan terhadap kinerja karyawan Royal Hotel Jember.
\end{abstract}

Kata Kunci: Pelatihan Kerja, Lingkungan Kerja, Komitmen Organisasi dan Kinerja Karyawan

\begin{abstract}
The aims of the research are the effect of job training, job environment and organizational commitment on employees' performence at Royal Hotel Jembe. The techniques of data collection used observation, interviews and questionnaries on 52 respondents used census techniques. Method using causal research. The result of test is founded coefficients of job training variables (X1) the significance count value of $0,001>0,05$ and $\mathrm{t}$ count $(3,533)>\mathrm{t}$ table $(1,677)$, job environment variable (X2) the significance count value $0,003>0,05$ and $t_{\text {count }}(3,125)>t_{\text {table }}(1,677)$, and organizational commitment variable $(\mathrm{X} 3)$ the significance count value $0,032>0,05$ dan $t_{\text {count }}(2,208)>t$ table $(1,677)$. The conclusion of the research indicates that job training has a significant effect on employee performence of Royal Hotel Jember, the job environment has significant effect on employee performence of Royal Hotel Jember, and the organizational commitment has a significant effect on employee performence of Royal Hotel Jember.
\end{abstract}

Keyword: job training, job environment, organizational commitment and employee performance 


\section{PENDAHULUAN}

Manajemen merupakan proses pendayagunaan seluruh sumber daya yang dimiliki organisasi untuk mencapai tujuan yang telah ditetapkan. Dengan meningkatkan kualitas sumber daya manusia diharapkan karyawan dapat bekerja secara produktif dan profesional sehingga kinerja yang dicapainya diharapkan akan lebih memuaskan sesuai standar kerja yang dipersyaratkan Tulus (2011:8). Untuk mewujudkan hal tersebut setiap organisasi maupun perusahaan akan selalu berusaha untuk mendukung terciptanya kinerja yang tinggi dari karyawan.

Menurut Rivai (2015:87), pelatihan secara singkat didefinisikan sebagai suatu kegiatan untuk meningkatkan kinerja saat ini dan kinerja dimasa mendatang. Pelatihan ini merupakan usaha-usaha yang sistematis untuk mengumpulkan informasi pada permasalahan kinerja dalam organisasi dan untuk mengoreksi kekurangan-kekurangan kinerja berkenaan dengan ketidakcocokan antara perilaku aktual dengan perilaku yang diharapkan. Menurut Sunyoto (2012:43) menyatakan bahawa lingkungan kerja adalah segala sesuatu yang ada dilingkungan yang dapat mempengaruhi dirinya dalam menjalankan tugas-tugas yang dibebankan. Lingkungan kerja yang menyediakan fasilitas-fasilitas yang dibutuhkan oleh para karyawan, maka karyawan yang bekerja akan semakin nyaman.

Menurut Robbins and Judges (2011:213), komitmen organisasional didefinisikan sebagai kekuatan yang bersifat relative dari individu dalam mengidentifikasikan keterlibatan dirinya kedalam bagian organisasi yang dicirikan oleh penerimaan nilai dan tujuan organisasi, ketersediaan berusaha demi organisai dan keinginan mempertahankan keanggotaan dalam organisasi.

Royal Hotel Jember merupakan salah satu hotel bintang 3 di kota Jember, yang berlokasi di Jl. Karimata No. 50 Kav. 2, Sumbersari, Kabupaten Jember. Peningkatan kemampuan karyawan pada Royal Hotel Jember dilakukan dengan menyelenggarakan program pelatihan kerja mengingat karyawan yang berasal dari latar belakang yang berbeda. Berikut bentuk-bentuk pelatihan kerja yang diberikan kepada karyawan Royal Hotel Jember.

Target kinerja juga dapat dilihat dari pekerjaan yang terjadi di Royal Hotel Jember dalam bentuk kinerja berbagai bagian pekerjaan. Berikut data kinerja karyawan Royal Hotel Jember. 
Tabel 1 Kinerja karyawan pada Royal Hotel Jember November - Desember 2016

\begin{tabular}{|c|c|c|c|c|c|}
\hline \multirow[t]{2}{*}{ No. } & \multirow[t]{2}{*}{$\begin{array}{l}\text { Jabatan } \\
\text { Karywan }\end{array}$} & \multirow{2}{*}{$\begin{array}{c}\text { Jumlah } \\
\text { Karyawan } \\
\text { (orang) }\end{array}$} & \multirow[t]{2}{*}{$\begin{array}{c}\text { Target } \\
(\%)\end{array}$} & \multicolumn{2}{|c|}{$\begin{array}{c}\text { Nilai rata-rata kinerja } \\
\text { karyawan }\end{array}$} \\
\hline & & & & $\begin{array}{c}\text { General } \\
\text { Aspect }(\%)\end{array}$ & $\begin{array}{c}\text { presensi } \\
\text { Aspect (\%) }\end{array}$ \\
\hline 1. & Front Office & 13 & 90 & 85 & 84 \\
\hline 2. & Accounting & 1 & 90 & 83 & 83 \\
\hline 3. & F\&B service & 10 & 90 & 87 & 82 \\
\hline 4. & Security & 3 & 90 & 85 & 83 \\
\hline 5. & House & 14 & 90 & 84 & 82 \\
\hline 6. & keeping & 8 & 90 & 86 & 84 \\
\hline 7. & $\begin{array}{l}\text { Kitchen } \\
\text { Engenering }\end{array}$ & 3 & 90 & 85 & 83 \\
\hline \multicolumn{4}{|c|}{ Nilai rata-rata kinerja karyawan } & 85 & 83 \\
\hline \multicolumn{4}{|c|}{$\begin{array}{l}\text { Nilai rata-rata kinerja bulan Januari- } \\
\text { Februari tahun } 2016\end{array}$} & 83 & 81 \\
\hline
\end{tabular}

Sumber: Hotel Royal Jember 2016

Menurut tabel 1 nilai rata-rata kinerja karyawan pada Royal Hotel masih di bawah target yang di tetapkan. Kinerja karyawan untuk setiap jabatanpun fluktuatif, nilai rata-rata kinerja karyawan dilihat dari general aspectnya yaitu sebesar 85\% dan presensi aspect sebesar $83 \%$. Untuk meningkatkan kinerja karyawan pada setiap jabatan agar sesuai dengan target yang ditetapkan, maka perlu diadakannya pelatihan untuk meningkatkan kemampuan dan keahlian para karyawan, menyediakan fasilitas yang dibutuhkan karyawan untuk menunjang kinerja dan menumbuhkan rasa komitmen karyawan terhadap perusahaan. Untuk itu penelitian ini akan meneliti seberapa besar pengaruh pelatihan kerja, lingkungan kerja dan komitmen organisasi terhadap kinerja karyawan pada Royal. Hotel Jember.

\section{TINJAUAN TEORITIS DAN EMPIRIS}

Sinambela (2016:7) sumber daya manusia merupakan suatu perencanaan, pengorganisasian, pengkoordinasian, pelaksanaan dan pengawasan terhadap pengadaan, pengembangan, pemberian balas jasa, pengintegrasian, pemeliharaan, dan pemisahan tenaga kerja dalam rangka mencapai tujuan organisasi.

\section{Pelatihan Kerja}

Menurut Rivai (2015:87), pelatihan secara singkat didefinisikan sebagai suatu kegiatan untuk meningkatkan kinerja saat ini dan kinerja di masa yang akan mendatang. 
Pelatihan ini merupakan usaha-usaha yang sistematis untuk mengumpulkan informasi pada permasalahan kinerja dalam organisasi dan untuk mengoreksi kekurangankekurangan kinerja berkenaan dengan ketidakcocokan antara perilaku aktual dengan perilaku yang diharapkan.

\section{Lingkungan Kerja}

Menurut Sunyoto (2012:43) menyatakan bahawa lingkungan kerja adalah segala sesuatu yang ada dilingkungan yang dapat mempengaruhi dirinya dalam menjalankan tugas-tugas yang dibebankan. Lingkungan kerja dalam organisasi atau perusahaan mempunyai peranan penting untuk kelancaran proses perusahaan karena lingkungan kerja yang baik tidak hanya dapat memuaskan karyawan dalam melaksanakan tugas, juga berpengaruh dalam meningkatkan karyawan.

\section{Komitmen Organisasi}

Komitmen organisasional (organizational commitment), didefinisikan sebagai suatu keadaan dimana seseorang karyawan memihak organisasi tertentu serta tujuantujuan dan keinginannya untuk mempertahankan keanggotaan dalam organisasi tersebut. Jadi, keterlibatan pekerjaan yang tinggi berarti memihak pada pekerjaan tertentu seseorang individu,sementara komitmen norganisasional yang tinggi berarti memihak organisasi yang merekrut individu tersebut. (Robbins, 2011:100).

\section{Kinerja Karyawan}

Menurut Mangkunegara (2008:145) kinerja adalah hasil kerja secara kualitas dan kuantitas yang dicapai oleh seorang pegawai dalam melaksanakan tugasnya sesuai dengan tanggung jawab yang diberikan kepadanya. Kinerja karyawan merupakan hasil kerja yang telah dicapai oleh seorang karyawan berdasarkan standar yang telah ditetapkan.k kinerja yang baik adalah kinerja yang mengikuti tata cara atau prosedur sesuai dengan standar yang telah ditetapkan.

\section{Kerangka Konseptual}

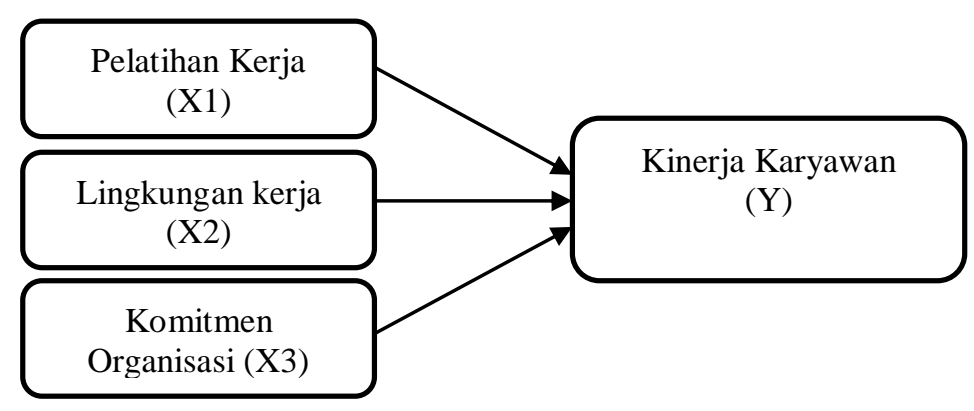


Penelitian ini juga merujuk pada penelitian empiris, Menurut Aruan (2015), hasil penelitian analisisnya menunjukkan bahwa pelatihan dan motivasi berpengaruh positif signifikan terhadap kinerja karyawan. Mamangkey (2015), hasil penelitian analisisnya menunjukkan bahwa Pelatihan, pengalaman dan lingkungan kerja secara parsial berpengaruh positif signifikan terhadap kinerja karyawan. Febrian (2016) hasil penelitian analisisnya menunjukkan bahwa pelatihan, kompensasi, dan komitmen organisasi berpengaruh positif signifikan terhadap kinerja karyawan. Maulidia (2017), hasil penelitian analisisnya menunjukkan bahwa Kompensasi, Lingkungan Kerja dan Gaya Kepemimpinan berpengaruh signifikan terhadap Kinerja Karyawan. Menurut Wahyudi (2015), hasil penelitiannya menunjukkan bahwa motivasi dan komitmen organisasi secara parsial berpengaruh positif signifikan terhadap kinerja karyawan. Hamzah (2016), hasil penelitiannya menunjukkan bahwa Komitmen Organisasi, Motivasi dan Disiplin Kerja berpengaruh positif dan signifikan terhadap kinerja karyawan.

\section{Hipotesis}

Berdasarkan pengertian dari ahli dan penelitian terdahulu, hipotesis dari penelitian ini adalah sebagai berikut :

H1 : Pelatihan kerja (X1) berpengaruh secara positif dan signifikan terhadap kinerja karyawan di Royal Hotel Jember.

H2 : Lingkungan kerja (X2) berpengaruh secara positif dan signifikan terhadap kinerja karyawan di Royal Hotel Jember.

H3 : Komitmen Organisasi (X3) berpengaruh secara positif dan signifikan terhadap kinerja karyawan di Royal Hotel Jember

\section{METODE PENELITIAN}

\section{Definisi Operasional}

\section{Pelatihan Kerja}

Pelatihan secara singkat didefinisikan sebagai suatu kegiatan untuk meningkatkan kinerja saat ini dan kinerja di masa yang akan mendatang. Indikatorindikator pelatihan menurut Mangkunegara (2013:62) diantaranya:
a) Jenis Pelatihan
b) Materi
c) Metode yang digunakan
d) Kualifikasi pelatih 


\section{Lingkungan Kerja}

Lingkungan kerja adalah segala keadaan yang berbentuk fisik dan terdapat disekitar tempat kerja yang mempengaruhi cara bekerja karyawan baik secara langsung maupun tidak langsung. Menurut Robbins (2011:150) indikator-indikator lingkungan kerja adalah :
a) Fasilitas kantor
b) Kondisi kerja
c) Hubungan antar sesama karyawan
d) Hubungan antara karyawan dengan pimpinan

\section{Komitmen Organisasi}

Komitmen organisasi dapat diartikan sebagai sejauh mana seseorang karyawan mengalami rasa kesatuan dengan organisasi mereka. Adapun indikator menurut Meyer \& Allen yang dikutip Spector (dalam Sopiah, 2008:163) adalah:
a) Affective commitment
b) Continuance commitment
c) Normative commitment

\section{Kinerja Karyawan}

Kinerja adalah hasil kerja secara kualitas dan kuantitas yang dicapai oleh seorang pegawai dalam melaksanakan tugasnya sesuai dengan tanggung jawab yang diberikan kepadanya. Indikator kinerja karyawan menurut Guritno dan Waridin (2005:120) adalah sebagai berikut:
a) Mampu meningkatkan target pekerjaan.
b) Mampu menyelesaikan pekerjaan tepat waktu.
c) Mampu menciptakan kreativitas dalam menyelesaikan pekerjaan.
d) Mampu meminimalkan kesalahan pekerjaan.

\section{Populasi dan Sampel}

Menurut Arikunto (2006:130) menyatakan populasi adalah keseluruhan objek penelitian jika seseorang ingin meneliti semua elemen yang ada pada wilayah penelitian maka penelitiannya merupakan penelitian populasi atau studi populasi atau sensus. Dalam penelitian ini yang menjadi populasi adalah karyawan Royal Hotel Jember yang berjumlah 52 karyawan. Arikunto (2006:131) apabila subjek kurang dari 100 orang maka diambil semua. Sehingga sampel penelitiannya merupakan penelitian populasi atau sensus. 


\section{HASIL DAN PEMBAHASAN}

\section{Deskriptif Analisis}

Responden dalam penelitian ini adalah seluruh karyawan Royal Hotel Jember yaitu berjumlah 52 karyawan. Karakteristik responden dalam penelitian ini yaitu karakteristik responden berdasarkan jenis kelamin dan dan karakteristik responden berdasarkan umur. jumlah responden yang menjadi karyawan Royal Hotel Jember yang berjenis kelamin pria lebih banyak disbanding jumlah responden wanita. Responden pria yaitu sebanyak 39 dan wanita yaitu sebanyak 13. Berdasarkan usia jumlah karyawan pada usia 18-22 tahun sebanyak 13 Orang, jumlah karyawan pada usia 23-27 tahun sebanyak 26 Orang, jumlah karyawan pada usia $>28$ tahun sebanyak 13 Orang.

\section{Uji Validitas}

Uji validitas digunakan untuk menguji sejauh mana ketepatan alat pengukur dapat mengungkapkan konsep gejala atau kejadian yang diukur. Item kuesioner dinyatakan valid apabila nilai $r$ hitung $>r$ table $(n-2)$ dan nilai signifikasi $<0,05$.

\section{Uji reliabilitas}

Uji reliabilitas digunakan untuk menguji sejauh mana keandalan suatu alat pengukur untuk dapat digunakan lagi untuk penelitian yang sama. Suatu variabel dikatakan reliabel apabila variabel tersebut memberikan nilai Cronbach Alpha > 0,700.

Tabel 2 Hasil Uji Validitas

\begin{tabular}{lcccccc}
\hline No & Variabel/indikator & \multicolumn{2}{c}{ kriteria 1 } & \multicolumn{2}{c}{ Kriteria 2 } & Keterangan \\
\cline { 3 - 5 } & Pelatihan kerja & r hitung & r tabel & Nilai sig & alpha & \\
1 & X1.1 & 0,563 & 0,2732 & 0,000 & 0,05 & Valid \\
2 & $\mathrm{X} 1.2$ & 0,576 & 0,2732 & 0,000 & 0,05 & Valid \\
3 & $\mathrm{X} 1.3$ & 0,663 & 0,2732 & 0,000 & 0,05 & Valid \\
4 & X1.4 & 0,573 & 0,2732 & 0,000 & 0,05 & Valid \\
& Lingkungan kerja & & & & & \\
1 & X2.1 & 0,560 & 0,2732 & 0,000 & 0,05 & Valid \\
2 & X2.2 & 0,543 & 0,2732 & 0,000 & 0,05 & Valid \\
3 & X2.3 & 0,587 & 0,2732 & 0,000 & 0,05 & Valid \\
4 & X2.4 & 0,720 & 0,2732 & 0,000 & 0,05 & Valid \\
& Komitmen organisasi & & & & & \\
1 & X3.1 & 0,711 & 0,2732 & 0,000 & 0,05 & Valid \\
2 & X3.2 & 0,698 & 0,2732 & 0,000 & 0,05 & Valid \\
3 & X3.3 & 0.685 & 0,2732 & 0,000 & 0,05 & Valid \\
& Kinerja Karyawan & & & & & \\
1 & Y.1 & 0,666 & 0,2732 & 0,000 & 0,05 & Valid \\
2 & Y.2 & 0,583 & 0,2732 & 0,000 & 0,05 & Valid \\
3 & Y.3 & 0,602 & 0,2732 & 0,000 & 0,05 & Valid \\
4 & Y.4 & 0,429 & 0,2732 & 0,000 & 0,05 & Valid \\
\hline
\end{tabular}

Sumber: Data Diolah 
Tabel 3 Hasil Uji Reliabilitas

\begin{tabular}{clccc}
\hline No & \multicolumn{1}{c}{ Variabel } & $\begin{array}{c}\text { Alpha } \\
\text { hitung }\end{array}$ & $\begin{array}{c}\text { Standa } \\
\text { r alpha }\end{array}$ & Keterangan \\
\hline 1 & Pelatihan Kerja $\left(\mathrm{X}_{1}\right)$ & 0,718 & 0,700 & Reliabel \\
2 & $\begin{array}{l}\text { Lingkungan Kerja } \\
\left(\mathrm{X}_{2}\right)\end{array}$ & 0,725 & 0,700 & Reliabel \\
3 & $\begin{array}{l}\text { Komitmen Organisasi } \\
\left(\mathrm{X}_{3}\right)\end{array}$ & 0,775 & 0,700 & Reliabel \\
4 & Kinerja Karyawan $(\mathrm{Y})$ & 0,701 & 0,700 & Reliabel \\
\hline
\end{tabular}

Sumber: Data Diolah.

\section{Analisis Regresi Linear Berganda}

Analisis regresi digunakan untuk menguji hipotesis tentang pengaruh secara parsial variabel bebas terhadap variabel terikat.

Tabel 4 Regresi Linear Berganda

\begin{tabular}{llccc}
\hline No & \multicolumn{1}{c}{ Variabel } & $\begin{array}{c}\text { Koefisien } \\
\text { Regresi }\end{array}$ & $\begin{array}{c}\mathbf{t} \\
\text { hitung }\end{array}$ & Signifikasi \\
\hline \multirow{2}{*}{$\mathbf{3}$} & Konstanta & 9,403 & 5,511 & 1 \\
$\mathbf{3}$ & $\begin{array}{l}\text { Lelatihan Kerja }\left(\mathrm{X}_{1}\right) \\
\text { Lingkungan Kerja }\end{array}$ & 0,396 & 3,533 & 0,001 \\
$\mathbf{4}$ & 0,332 & 3,125 & 0,000 \\
& $\begin{array}{l}\text { Komitmen Organisasi } \\
\left(\mathrm{X}_{3}\right)\end{array}$ & 0,214 & 2,208 & 0,032 \\
\hline
\end{tabular}

Sumber: Data Diolah

Berdasarkan tabel 5, dapat diketahui persamaan regresi yang terbentuk adalah :

$$
Y=9,403+0,396 X_{1}+0,332 X_{2}+0,214 X_{3}
$$

\section{Uji Normalitas}

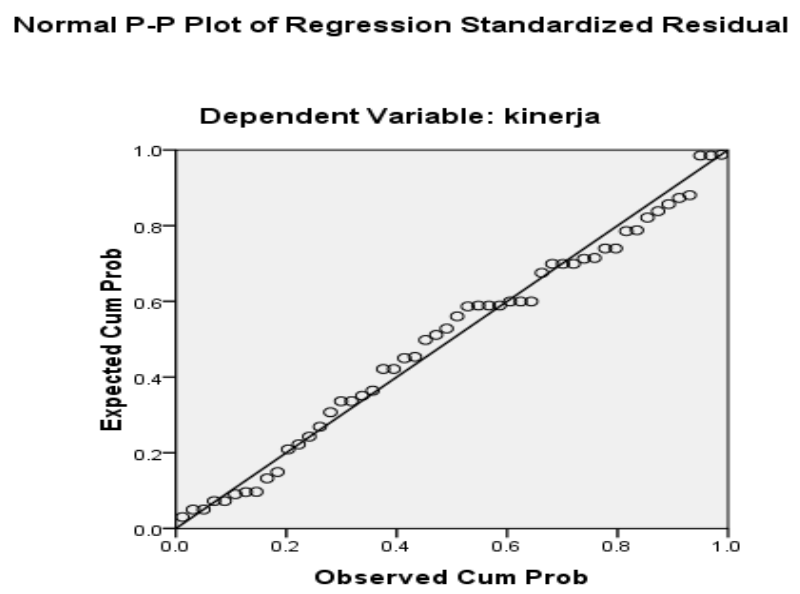

Gambar 1. Hasil Uji Normalitas 
Setelah dilakukan pengujian ternyata semua data terdistribusi secara normal, sebaran data berada disekitar garis diagonal. Hal ini menunjukkan bahwa model regresi dalam penelitian ini memenuhi asumsi normalitas.

\section{Uji Multikolinearitas}

Tabel 5 Hasil Uji Multikolinearitas

\begin{tabular}{clcc}
\hline No & \multicolumn{1}{c}{ Variabel } & $\begin{array}{c}\text { Nilai } \\
\text { Tolerance }\end{array}$ & $\begin{array}{c}\text { Nilai } \\
\text { VIF }\end{array}$ \\
\hline $\mathbf{1}$ & Pelatihan Kerja $\left(\mathrm{X}_{1}\right)$ & 0,662 & 1,511 \\
$\mathbf{2}$ & Lingkungan Kerja $\left(\mathrm{X}_{2}\right)$ & 0,630 & 1,587 \\
$\mathbf{3}$ & $\begin{array}{l}\text { Komitmen Organisasi } \\
\left(\mathrm{X}_{3}\right)\end{array}$ & 0,917 & 1,090 \\
\hline
\end{tabular}

Sumber: Data Diolah.

Dari tabel 6 menunjukkan bahwa nilai VIF semua variabel bebas dalam penelitian ini lebih kecil dari 10 sedangkan nilai toleransi semua variabel bebas lebih dari 10\% yang berarti tidak terjadi kolerasi antar variabel bebas, dengan demikian dapat disimpulkan bahwa tidak terdapat gejala multikolinearitas antar variabel bebas dalam model regresi.

\section{Uji Heteroskedastisitas}

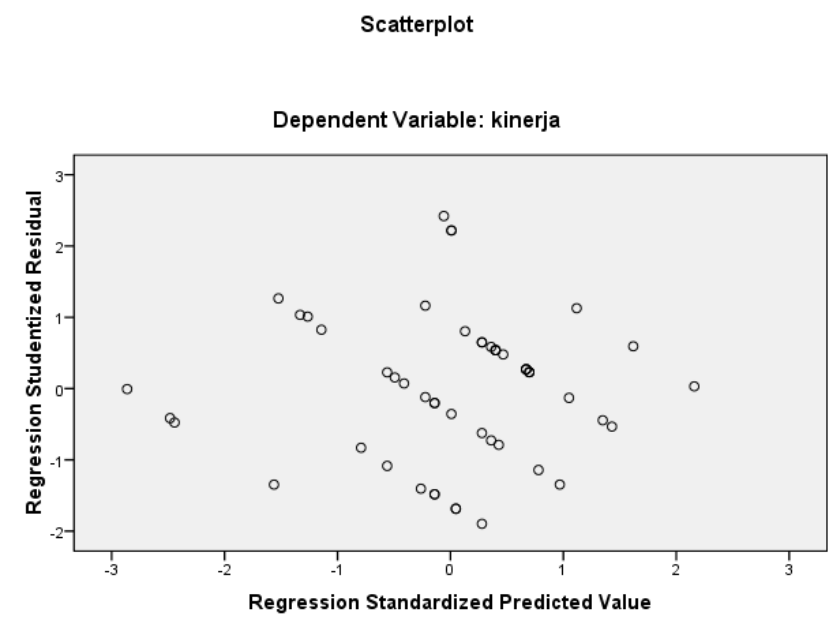

Gambar 2 Hasil Uji Heteroskedastisitas

Dari hasil uji heteroskedastisitas yang telah dilakukan, ternyata titik-titik menyebar secara acak, tidak membentuk suatu pola tertentu yang jelas serta tersebar baik diatas maupun dibawah angka nol pada sumbu Y. hal ini berarti tidak terjadi penyimpangan 
asumsi klasik heteroskedastisitas pada model regresi yang dibuat, dengan kata lain menerima hipotesis homoskedastisitas.

\section{Uji Linearitas}

Uji terhadap linearitas berguna untuk mengetahui kebenaran bentuk model empiris yang digunakan dan menguji variabel yang relevan untuk dimasukkan dalam model empiris. Dengan kata lain uji linear bermanfaat untuk mengetahui adanya kesalahan dalam spesifikasi model.

\section{Tabel 6 Hasil Uji Linearitas}

\begin{tabular}{clcc}
\hline No & \multicolumn{1}{c}{ Variabel } & Nilai F & Keterangan \\
\hline $\mathbf{1}$ & Kinerja karyawan dengan pelatihan kerja & 0,150 & Linear \\
$\mathbf{2}$ & $\begin{array}{l}\text { Kinerja karyawan dengan lingkungan } \\
\text { kerja }\end{array}$ & 1,784 & Linear \\
$\mathbf{3}$ & $\begin{array}{l}\text { Kinerja karyawan dengan komitmen } \\
\text { organisasi }\end{array}$ & 0,970 & Linear \\
\hline
\end{tabular}

Sumber : Data Diolah

\section{Uji Hipotesis}

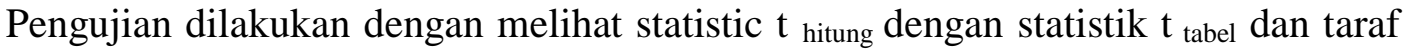
signifikasi ( $p$-value), jika taraf signifikasi yang dihasilkan dari perhitungan dibawah 0,005 maka hipotesis diterima, sebaliknya jika taraf signifikasi hasil hitung lebih besar dari 0,05 maka hipotesisi ditolak.

Tabel 7 Uji Hipotesis

\begin{tabular}{clccccc}
\hline No & \multicolumn{1}{c}{ Variabel } & $\begin{array}{c}\text { Signifikansi } \\
\text { Hitung }\end{array}$ & $\begin{array}{c}\text { Taraf } \\
\text { Signifkansi }\end{array}$ & $\mathrm{t}_{\text {hitung }}$ & $\mathrm{t}_{\text {tabel }}$ & Keterangan \\
\hline $\mathbf{1}$ & Pelatihan Kerja & 0,001 & 0,05 & 3,533 & 1,677 & Signifikan \\
$\mathbf{2}$ & $\begin{array}{l}\text { Lingkungan } \\
\text { kerja }\end{array}$ & 0,003 & 0,05 & 3,125 & 1,677 & Signifikan \\
$\mathbf{3}$ & $\begin{array}{l}\text { Komitmen } \\
\text { Organisasi }\end{array}$ & 0,032 & 0,05 & 2,208 & 1,677 & Signifikan \\
\hline
\end{tabular}

Sumber : Data Diolah.

Dari tabel 7, diketahui bahwa nilai signifikansi hitung dari setiap variabel kurang dari taraf signifikansi $(0,05)$. Untuk variabel pelatihan kerja nilai signifikansi hitung sebesar 0,001>005 jadi berpengaruh signifikan, variabel lingkungan kerja nilai signifikansi sebesar $0,003>0,05$ jadi berpengaruh signifikan, variabel komitmen organisasi nilai signifikansi $0,032>0,05$ jadi berpengaruh signifikan. 


\section{Uji Koefisien Determinasi $\left(\mathbf{R}^{2}\right)$}

Koefisien determinasi merupakan besaran yang menunjukkan besarnya variasi variabel dependen yang dapat dijelaskan oleh variabel independennya.

Tabel 8 Uji Koefisien Determinasi $\left(\mathbf{R}^{2}\right)$

\begin{tabular}{clc}
\hline No & \multicolumn{1}{c}{ Kriteria } & Koefisien \\
\hline $\mathbf{1}$ & $R$ & 0,716 \\
$\mathbf{2}$ & $R$ Square & 0,513 \\
$\mathbf{3}$ & Adjusted $R$ Square & 0,483 \\
\hline
\end{tabular}

Dari tabel 8, diketahui hasil perhitungan regresi bahwa koefisien determinasi yang diperoleh sebesar 0,483. Hal ini berarti 48,3\% variasi variabel kinerja karyawan dapat dijelaskan oleh pelatihan kerja, lingkungan kerja dan komitmen organisasi, sedangkan sisanya 0,517 atau 51,7\% diterangkan oleh variabel lain yang tidak diajukan dalam penelitian ini.

\section{Pembahasan}

\section{a. Pengaruh Pelatihan Kerja Terhadap Kinerja Karyawan}

Hasil pengujian membuktikan bahwa pelatihan kerja mempunyai pengaruh terhadap kinerja karyawan. Artinya bahwa pelatihan kerja yang meliputi jenis pelatihan, materi, metode yang digunakan dan kualifikasi pelatih berpengaruh terhadap kinerja karyawan. Hasil ini mendukung teori indikator yang dikemukakan oleh Mangkunegara (2013:62). Hasil ini juga mendukung penelitian sebelumnya oleh Aruan (2015) Mamangkey (2015) dan Febrian (2016).

\section{b. Pengaruh Lingkungan Kerja Terhadap Kinerja Karyawan}

Hasil pengujian membuktikan bahwa lingkungan kerja mempunyai pengaruh terhadap kinerja karyawan. Artinya bahwa lingkungan kerja yang meliputi fasilitas kantor, kondisi kerja, hubungan antar sesama karyawan, dan hubungan antara karyawan dengan atasan berpengaruh terhadap kinerja karyawan. Hasil ini mendukung teori indikator yang dikemukakan Robbins (2011:150). Hasil ini juga mendukung penelitian sebelumnya oleh Mamangkey (2015) dan Maulidia (2017).

\section{c. Pengaruh Komitmen Organisasi Terhadap Kinerja Karyawan}

Hasil pengujian membuktikan bahwa komitmen organisasi mempunyai pengaruh terhadap kinerja karyawan. Artinya bahwa lingkungan kerja yang meliputi 
Affective commitment, Continuance commitment dan Normative commitment, berpengaruh terhadap kinerja karyawan. Hasil ini mendukung teori indikator yang dikemukakan Meyer \& Allen yang dikutip Spector (dalam Sopiah, 2008:163). Hasil ini juga mendukung penelitian sebelumnya oleh Wahyudi (2015), Hamzah (2016) dan Febrian (2016).

\section{KESIMPULAN DAN SARAN}

\section{Kesimpulan}

1. Pelatihan kerja berpengaruh secara positif dan signifikan terhadap kinerja karyawan pada Royal Hotel Jember. Hal ini berarti semakin baik pelatihan kerja yang diberikan perusahaan maka akan meningkatkan kinerja karyawan pada Royal Hotel jember.

2. Lingkungan kerja berpengaruh secara positif dan signifikan terhadap kinerja karyawan pada Royal Hotel Jember. Hal ini berarti semakin baik lingkungan kerja yang diberikan perusahaan maka akan meningkatkan kinerja karyawan pada Royal Hotel jember.

3. Komitmen organisasi berpengaruh secara positif dan signifikan terhadap kinerja karyawan pada Royal Hotel Jember. Hal ini berarti semakin baik komitmen organisasi maka akan meningkatkan kinerja karyawan pada Royal Hotel jember.

\section{Saran}

\section{Bagi Perusahaan}

1. Diharapkan Royal Hotel Jember lebih meningkatkan pelatihan kerja dengan memberikan pelatihan sesuai dengan bidang pekerjaan yang digeluti.

2. Diharapkan Royal Hotel Jember memberikan fasilitas lingkungan kerja ternyaman bagi karyawan, agar para karyawan merasa nyaman dan tenang saat bekerja.

3. Diharapkan Royal Hotel Jember menumbuhkan rasa komitmen bagi para karyawan, agar para karyawan memiliki rasa keterlibatan yang nantinya akan meningkatkan kinerja karyawan.

\section{Bagi Peneliti Selanjutnya}

Diharapkan bagi penelitian selanjutnya diperluas dan lebih dalam dengan menambah objek atau variabel penelitian agar mendapatkan gambaran yang lebih lengkap, sehingga hasil penelitian yang akan dating lebih sempurna dari penelitian ini. 


\section{DAFTAR PUSTAKA}

Agus Tulus, Moh. 2011. Manajemen Sumber Daya Manusia, Buku Panduan Mahasiswa, Jakarta: PT. Gramedia Pustaka Utama

Anwar Prabu Mangkunegara, 2008 Manajemen Sumber Daya Manusia, cetakan kelima, Penerbit PT. Remaja Rosdakarya. Bandung.

Anwar Prabu Mangkunegara., 2013 Manajemen Sumber Daya Manusia Perusahaan, Remaja Rosdakarya, Bandung

Febrian Deni Prima, 2016. Pengaruh paltihan, kompensasi dan komitmen organisasi terhadap kinerja karyawan pada PT PETCO Pratama Semarang. E-jurnal Universitas Dian Nuswantoro.

Guritno, Bambang dan Waridin. 2005. Pengaruh Persepsi Karyawan Mengenai Perilaku Kepemimpinan, Kepuasan Kerja Dan Motivasi Terhadap Kinerja. JRBI. Vol 1.

Hamzah Nur, 2015. Pengaruh komitmen organisasi, motivasi dan disiplin kerja terhadap kinerja karyawan di PT. Primatama Mulya Jaya (PMJ) Kabupaten Pasaman Barat. E-jurnal STIE Pasaman Simpang Empat Pasaman barat.

M. A.Tulus. 2011. Manegemen Sumber Daya Manusia. Gramedia Pustaka Utama, Jakarta.

Mamangkey Junita Trisofi, 2015. Pengaruh pelatihan, pengalaman dan lingkungan kerja terhadap kinerja karyawan pada PT Bangun Wenang Beverages Company Manado. E-journal Universitas Sam Ratulangi Manado. ISSN 2303-1174

Rivai 2015. Performance Appraisal Sistem yang Tepat Untuk menilai Kinerja Karyawan dan Meningkatkan Daya Saing Perusahaan. PT Raja Grafindo Persada, Jakarta

Robbins. Stephen. P. 2011. Manajemen. Edisi kedelapan. Jilid 2. Jakarta: PT. Indeks.

Robbins, Stephen.P. dan Timothy A.Judge. 2008. Perilaku Organisasi Alih Bahasa Benjamin Molan, Edisi Bahasa Indonesia, PT.Intan Klaten.

Robbins, 2011, Perilaku Organisasi ed 12,: Salemba Empat, Jakarta

Rivai, Veithzal. 2009. Manajemen Sumber Daya Manusia Untuk Perusahaan Dari Teori ke Praktik. Jakarta: Raja Grafindo Persada

Sinambela, Lijan Poltak. 2016. Manajemen Sumber Daya Manusia. Jakarta: PT Bumi Aksara

Sunyoto, Danang. 2012. Manajemen Sumber Daya Manusia .Yogyakarta: CAPS (Center for Academic Publishing Service)

Sopiah. 2008. Perilaku Organisasi, Yogyakarta : Andi 